\title{
A Cross-Cultural View Towards The Ethical Dimensions Of Electronic Monitoring Of Employees: Does Gender Make A Difference?
}

\author{
Raymond E. Taylor, Louisiana State University, USA
}

\begin{abstract}
This manuscript presents the results of a study which examined the ethical dimensions of electronic monitoring of employees from a cross-cultural perspective comparing participants from Taiwan with those from the United States. The results of the study suggest that gender differences exist between Taiwanese and American participants' attitudes concerning the ethics of electronic monitoring of employees. The study suggests that monitoring with notice was an important parameter in determining how ethical electronic monitoring of employees was viewed by the respondents.
\end{abstract}

Keywords: Cross-cultural Ethical Dimensions; Gender Differences

\section{INTRODUCTION}

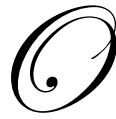

ne of the most important emerging regional markets is the Pacific-Rim. Within this Pacific-Rim regional market, the Chinese business environment stands as the catalyst for the region's future economic growth and most likely the next superpower (Paynich, 2004). The Chinese business environment includes the People's Republic of China (including Hong Kong) and the Republic of China, or more commonly known as Taiwan. From the author's experience of teaching at a leading private Taiwan university, Taiwan and PRC share an interwoven relationship. First, a number of Taiwanese business firms have dual operations in Taiwan and in the PRC. Second, between the two countries, there are significant family ties. A number of Taiwanese have relatives in the PRC who they visit on a regular basis. Third, a number of universities and colleges in Taiwan have "sister" universities in the PRC and they host joint activities involving faculty traveling extensively between the two countries. Fourth, because of the shared cultural heritage between the two countries, they will inevitably be drawn economically closer as the PRC continues to develop economically. Lastly, the Taiwanese market represents a prelude for entering the PRC market. A foreign company wishing to enter into the PRC market could select the strategy of partnering with a Taiwanese company first. The conceptual logic for selecting this strategy is twofold. For a number of years, the Taiwan business environment has been somewhat "westernized" and accustomed to interacting with foreign companies. Secondly, Taiwan companies may have established relationships with existing PRC partners that would expedite a foreign company's entry into the PRC market. To remain competitive in the global business environment, international businesses have to develop, within their executive leadership teams, a global mindset (Lynton and Thogersen, 2006). Therefore, to successfully enter and be competitive within the Pacific-Rim regional market place, foreign companies have to develop, within their executives, a Chinese mindset of administration. For example, Chinese executives tend to view managerial decision making holistically rather than linearly (Lynton and Thogersen, 2006). The basis for much of Chinese social status within the business organization centers on being part of a trusted circle (Lynton and Thogersen, 2006). In developing partnerships between Chinese and foreign companies, it is important to be sensitive to the mindsets of both parties, especially when merging organizational policies. With this in mind, this article presents the results of a study examining the attitudes of Taiwanese and American study participants regarding the ethics of electronically monitoring employees. 


\section{RESEARCH RATIONALE AND METHODOLOGY}

Business executives have always monitored their employees' behavior. Electronic monitoring may be especially useful in training and improving productivity (Blylinsky, 1991, and Laabs, 1992). However, critics of electronic monitoring suggest that the more obtrusive forms of electronic monitoring can lead to elevated levels of stress, decreased job satisfaction and quality of work, decreased levels of customer service and poor quality (Kallman, 1993). Electronic monitoring, by imposing excess control over employees' behavior, can alienate employees and develop a feeling of working in a modern "sweatshop" (Kidwell and Bennett, 1994). Employers have the legal right to electronically monitor their employees (Kelly, 2001). The question is not whether or not employers can electronically monitor their employees, but rather "how should it be done?"

The procedures used in electronically monitoring employees are very important, particularly in how employees view them. The procedures for electronically monitoring employees must be designed with fairness and ethics in mind. Electronic monitoring certainly raises ethical dilemmas for employers. Electronic monitoring systems must be consistent, free from bias, relevant, provide feedback, job-related, and, above all, perceived as ethical and fair (Kidwell and Bennett, 1994). The subject of electronic monitoring of employees should be a concern for executives as their companies become involved with foreign companies, especially in joint venture arrangements. Within the Chinese business environment, it would be helpful to understand the Chinese mindset concerning electronic monitoring of employees.

A number of studies have examined cross-cultural ethical business issues within the Chinese business environment. Ma explored cross-cultural differences in business ethics between China (People's Republic of China) and Canada (2010). The results from Ma's study suggest more gender differences from Canadian respondents than from Chinese respondents. Roxas and Stoneback considered the issue of gender across cultures in ethical decisionmaking. A sample of junior and senior accounting students from eight countries was taken (U.S.A, Canada, Australia, China, Philippines, Thailand, Germany, and Ukraine, 2004). One interesting outcome of Roxas and Stoneback's study was that, overall, males were significantly less ethical than females, except in China where females are less likely to behave ethically (2004, p. 161). In another study, Redfern and Crawford sampled Chinese managers from the PRC and administered the Forsyth's (1980) Ethics Position Questionnaire with them (2004). One result from their study indicates regional differences between Chinese managers; i.e., managers in South China scored different than managers in North China (Refern and Crawford, 2004, p. 208). In yet another study, Snell and Herndon examined the effective use of Code of Ethics by Hong Kong companies (2004). From their research, it appears that cultural factors (power distance and traditional legalist assumptions) account for a gap between adopting Code of Ethics and adherence to them (Snell and Herndon, 2004, p. 75). Chen-Fong Wu studied business ethics operation between Taiwan and PRC enterprises (2004). One observation made by Wu was the burden of the communist system in PRC as an obstacle to practicing sound ethical decisions for Chinese firms (2004, p. 241). In noting one last study, Douglas and Wier compared Chinese and U.S. managers concerning cultural and ethical effects in budgeting systems (2005). Douglas and Wier developed a model of cultural effects on budgeting systems as influenced by culture-specific work-related and ethical values. The data from their study, for the most part, supported research model by Douglas and Wier (2005, p. 170). Therefore, the results of the study presented in this article add to the above research by exploring the ethical dimensions of electronic monitoring of employees in comparison between Taiwanese and American participants.

Based on previous research, the study reported in this article addresses two research questions: (1) Are there significant gender differences between the attitudes of Taiwanese and American business people with respect to their ethical views of electronic monitoring? and (2) Does "giving notice" versus "secretly monitoring" make a significant difference in the ethical dimension of electronic monitoring?

The questionnaire used in this study was based on one developed by Vaught, Taylor, and Vaught (2000) as presented in an article entitled, "The Attitudes of Managers Regarding the Electronic Monitoring of Employee Behavior: Procedural and Ethical Considerations." The research statements of the questionnaire are presented in Table 1. The questionnaire was translated into Chinese by using the "Parallel Translation" method (Cateora and Graham, 2002, p. 220). Two samples were collected - one in Taiwan and one in the United States. In Taiwan, 500 questionnaires were distributed to students in MBA and Executive MBA classes at four universities in Northern 
Taiwan (part of a larger proprietary study). Of the 500 questionnaires, 220 were successfully returned for a response rate of $44 \%$. All of these respondents were college graduates with $60 \%$ male and $40 \%$ female. The average age of the male respondents was 32.5 and for the females, it was 28.3 .

In the United States, 500 questionnaires were also distributed to students in MBA and Executive MBA classes at two public and two private universities. Of these 500 questionnaires, 230 were successfully returned (120 from the public and 110 from the private) for a response rate of $46 \%$. All of these respondents were also college graduates with $45 \%$ male and 55\% female. The average age of the male respondents was 29.5 and for the females, it was 33.3.

Table 1: Ethical Dimensions Of Electronic Monitoring Of Employees - Taiwan And United States Gender Differences

\begin{tabular}{|c|c|c|c|c|c|}
\hline \multirow[b]{2}{*}{ Research Statements } & \multicolumn{5}{|c|}{ Mean average Level of Response * } \\
\hline & $\begin{array}{l}\text { Taiwan } \\
\text { Women }\end{array}$ & $\begin{array}{l}\text { Taiwan } \\
\text { Men }\end{array}$ & $\begin{array}{c}\text { USA } \\
\text { Women }\end{array}$ & $\begin{array}{l}\text { USA } \\
\text { Men }\end{array}$ & $\begin{array}{c}\text { Significance } \\
\text { Between } \\
\text { Groups** }\end{array}$ \\
\hline $\begin{array}{l}\text { 1. The electronic monitoring of an employee's work related } \\
\text { activities should be done occasionally rather than on a continuous } \\
\text { basis. }\end{array}$ & 3.85 & 3.35 & 4.15 & 3.87 & 0.01 \\
\hline $\begin{array}{l}\text { 2. Employees should be given notice (such as a blinking light on a } \\
\text { telephone) each time they are being electronically monitored. }\end{array}$ & 4.20 & 3.92 & 4.85 & 4.55 & 0.01 \\
\hline $\begin{array}{l}\text { 3. The secret video monitoring of an employee in his or her work } \\
\text { area is ethical. }\end{array}$ & 2.15 & 3.41 & 1.50 & 2.16 & 0.001 \\
\hline $\begin{array}{l}\text { 4. Giving employees written notice that they will be electronically } \\
\text { monitored sometime in the future is adequate warning. }\end{array}$ & 4.85 & 4.45 & 4.65 & 3.95 & 0.01 \\
\hline $\begin{array}{l}\text { 5. The collection of data, with notice, by a superior from an } \\
\text { employee's computer for later review is ethical. }\end{array}$ & 4.83 & 4.73 & 4.20 & 3.92 & 0.01 \\
\hline $\begin{array}{l}\text { 6. The simultaneous monitoring, with notice, by a superior of an } \\
\text { employee's computer screen is ethical. }\end{array}$ & 4.80 & 4.46 & 4.63 & 4.27 & 0.05 \\
\hline $\begin{array}{l}\text { 7. The secret simultaneous monitoring by a superior of an } \\
\text { employee's emails is ethical. }\end{array}$ & 2.05 & 3.85 & 2.01 & 2.87 & 0.01 \\
\hline $\begin{array}{l}\text { 8. It is ethical for a superior to listen-in, with notice, on an } \\
\text { employee's business related telephone calls. }\end{array}$ & 4.35 & 4.65 & 4.25 & 4.13 & 0.05 \\
\hline $\begin{array}{l}\text { 9. The monitoring, with notice, at a later time period by a superior } \\
\text { of an employee's emails is ethical. }\end{array}$ & 4.57 & 4.83 & 4.43 & 4.23 & 0.05 \\
\hline $\begin{array}{l}\text { 10. The secret collection of data from an employee's computer at a } \\
\text { later time period for review by a superior is ethical. }\end{array}$ & 2.05 & 3.71 & 1.15 & 2.71 & 0.01 \\
\hline $\begin{array}{l}\text { 11. It is ethical for a superior to secretly listen-in on an employee's } \\
\text { business related telephone calls. }\end{array}$ & 3.55 & 4.55 & 3.15 & 4.75 & 0.01 \\
\hline $\begin{array}{l}\text { 12. The monitoring, with notice, at a later time period by a } \\
\text { superior of an employee's computer screen is ethical. }\end{array}$ & 4.59 & 4.65 & 3.90 & 4.00 & 0.01 \\
\hline $\begin{array}{l}\text { 13. It is ethical for a superior to secretly record an employee's } \\
\text { business related telephone calls for later review. }\end{array}$ & 3.65 & 4.25 & 2.20 & 4.10 & 0.01 \\
\hline $\begin{array}{l}\text { 14. The secret simultaneous monitoring by a superior of an } \\
\text { employee's computer screen is ethical. }\end{array}$ & 2.22 & 4.40 & 2.10 & 2.90 & 0.01 \\
\hline $\begin{array}{l}\text { 15. The simultaneous monitoring, with notice, by a superior of an } \\
\text { employee's emails is ethical. }\end{array}$ & 4.25 & 4.85 & 4.09 & 4.69 & 0.05 \\
\hline $\begin{array}{l}\text { 16. It is ethical for a superior to record, with notice an employee's } \\
\text { business related telephone calls for later review. }\end{array}$ & 4.61 & 4.85 & 4.27 & 4.85 & 0.05 \\
\hline $\begin{array}{l}\text { 17. The secret monitoring at a later time period by a superior of an } \\
\text { employee's computer screen is ethical. }\end{array}$ & 2.05 & 3.09 & 1.85 & 2.43 & 0.01 \\
\hline $\begin{array}{l}\text { 18. The secret monitoring at a later time period by a superior of an } \\
\text { employee's emails is ethical. }\end{array}$ & 2.11 & 2.83 & 1.53 & 2.43 & 0.01 \\
\hline
\end{tabular}




\section{DISCUSSION OF THE RESULTS}

The questionnaire contains 18 statements and the respondents were asked to indicate their opinion of each statement along a five-point scale: 1=strongly disagree, $2=$ disagree, $3=$ uncertain, $4=$ agree, and 5=strongly agree. Mean scores between the Taiwanese respondents and the American respondents were tested for significance by using one-way analysis of variance and a Bonferroni test of difference between means. On all 18 statements, there was a significant difference between the Taiwanese and American respondents.

The first four statements were of general nature to lead into the more specific statements. On Statement 1, the four groups of respondents agreed that the electronic monitoring of employees should be done occasionally rather than continuously. The American respondents agreed more to this statement than the Taiwanese respondents. In addition, American women were significantly different from Taiwanese men. For Statement 2, the American respondents, again, agreed more than the Taiwanese respondents that "employees should be given notice each time they are being electronically monitored." Taiwanese men agreed the least with this statement and were significantly different from the other groups. Statement 3 says, "The secret video monitoring of an employee in his or her work area is ethical." The respondents disagreed with the Statement 3 with the American respondents disagreeing to a greater degree than the Taiwanese respondents. Taiwanese men and American women were, again, significantly different from each other. Statement 4 indicates that giving employees written notice that they will be electronically monitored sometime in the future is adequate warning. Respondents from both countries agreed with Statement 4; but the Taiwanese respondents did so at a higher level. With Statement 4, Taiwanese and American women were significantly different from each category of men respondents.

The remaining 14 statements focus on four areas of electronic monitoring - collection of data on an employee's computer, monitoring telephone usage, monitoring email usage, and monitoring computer screen activity.

Statements 5 and 10 consider the ethics of an employer collecting data from employees' computers, either with notice or secretly. The respondents strongly agree with Statement 5 that the collection of data, with notice by a superior, from an employee's computer is ethical. The Taiwanese respondents agreed more strongly with this statement than the American respondents and Taiwanese women respondents were significantly different from both American men and women. With Statement 10, respondent groups from both countries considered it unethical for the secret collection of data by a superior from an employee's computer. The American respondents more strongly expressed this position than the Taiwanese respondents. With Statement 10, Taiwanese and American women were significantly different from the men respondents.

Statements 6, 12, 14, and 17 look at the issue of monitoring employees' computer screens from two perspectives - "simultaneous" versus "at a later time" and "with notice" versus "secretly." The results indicate that the respondents expressed similar views regardless if the monitoring was done "simultaneous" or "at a later time" period. The striking difference is again on the issue of giving notice versus secret monitoring. The Taiwanese respondents expressed stronger support for giving notice than the American respondents. There were also noteworthy gender differences. With Statement 6, Taiwanese and American women were again significantly different from the men respondents. However, with Statements 12, 14, and 17, Taiwanese men were significantly different from all of the other groups.

Statements 7, 9, 15, and 18 examine the monitoring of employees' email usage. This is examined from the perspectives of "simultaneous vs. later review" and "with notice vs. secret" monitoring. Again, the issue of "simultaneous or later review" appears not to be a concern for the respondents, but secret monitoring without notice of employees' emails is a major concern. Taiwanese and American women were significantly different from the men respondents on Statement 7 and 18. Taiwanese men were significantly different from the other groups on Statement 9. On Statement 15 Taiwanese men and American women were significantly different from each other.

Statements $8,11,13$, and 16 address the monitoring of employees' telephone usage along the same dimensions of "simultaneous vs. later review" and "with notice vs. secret." The results suggest that it does not matter if the monitoring is done simultaneous or at a later time period, as long as notice is given to the employees 
and the monitoring is not done secretly. For Statement 8 , Taiwanese men were significantly different from the other groups and Taiwanese and American men were significantly different from the women respondents on Statement 11. Taiwanese and American women were significantly different from the men respondents on Statement 13; while the American women were significantly different from the other groups on Statement 16.

\section{CONCLUSION}

In considering the two research questions, the following observations can be made. On question 1: Are there significant gender differences between the attitudes of Taiwanese and American business people with respect to their ethical views of electronic monitoring? The results suggest gender differences on all of the research statements. Taiwanese and American women respondents were significantly different from their men counterparts on 8 out of the 18 statements. Taiwanese men were significantly different from the other three groups on 6 out of the 18 statements. American women were significantly different from Taiwanese men on 3 statements; while American women were significantly different from the other 3 groups on 1 statement. Reasons behind these differences would be speculative and would require additional research. It would be reasonable to assume that cultural differences would explain a part of these differences.

With respect to the second research question, it asks, "Does 'giving notice' versus 'secretly monitoring' make a significant difference in the ethical dimension of electronic monitoring?" All four respondent groups expressed adamant views that the secret monitoring of employees' behavior is unethical. Therefore, this study suggests that the respondents' view of the electronic monitoring of employees would be ethical as long as prior notice is provided to the employees. Companies wishing to operate within the Chinese business environment as part of the Pacific Rim regional market should not have problems with the electronic monitoring of their employees, as long as it is not done secretly.

\section{AUTHOR INFORMATION}

Raymond E. Taylor (Ph.D., Southern Illinois University at Carbondale) is professor of marketing at LSU in Shreveport and has published over 60 refereed journal and proceedings articles. He has been a visiting professor of marketing at the University of Hawaii in Hilo and at Chung Yuan Christian University in Chung Li, Taiwan. E-mail: raymond.taylor@sus.edu

\section{REFERENCES}

1. Bylinsky, G., "How Companies Spy on Employees,” Fortune, Nov. 14, Pages 131-141, 1991.

2. Cateora, Philip R. and John L. Graham, International Marketing, $11^{\text {th }}$ ed. McGraw-Hill Irwin Publishing, New York, 2002.

3. Douglas, Patricia Casey and Benson Wier,. "Cultural and Ethical Effects in Budgeting Systems: A Comparison of U.S. and Chinese Managers," Journal of Business Ethics, Volume 60 (Summer), Pages 159174, 2005.

4. Forsyth, D. R., “A Taxonomy of Ethical Ideologies,” Journal of Personality and Social Psychology, Volume 39, Number 1, Pages 175-184, 1980.

5. Kallman, E., "Electronic Monitoring of Employees: Issues and Guidelines," Journal of Systems Management, (June), Pages 17-21, 1993.

6. Kelly, Eileen P., "Electronic Monitoring of Employees in the Workplace," National Forum, Volume 81, Number 2, Pages 4-6, 2001.

7. Kidwell, Rowland E. and Nathan Bennett, "Electronic Surveillance as Employee Control: A Procedural Justice Interpretation," The Journal of High Technology Management Research, Volume 5, Number 1, Pages 39-57, 1994.

8. Laabs, J. J., “Surveillance: Tool or Trap?”, Personnel Journal, (June), Pages 96-104, 1992.

9. Lynton, Nandani and Kirsten Hogh Thogersen, "How China Transforms an Executive's Mind," Organizational Dynamics, Volume 35, Number 2, Pages 170-181, 2006.

10. Ma, Zhenzhong, "The SINS in Business Negotiations: Explore the Cross-Cultural Differences in Business Ethics between Canada and China," The Journal of Business Ethics, Volume 91, Pages 123-135, 2010. 
11. Paynich, Vitisia, "A Closer Look at China," Electronic Retailer, Volume 1, Number 2, Pages 26-31, 2004.

12. Redfern, Kylie and John Crawford, "An Empirical Investigation of the Ethics Position Questionnaire in the People's Republic of China," Journal of Business Ethics, Volume 50, Pages 199-210, 2004.

13. Roxas, Maria L. and Jane Y. Stoneback, "The Importance of Gender across Cultures in Ethical DecisionMaking," Journal of Business Ethics, Volume 50, Pages 149-165, 2004.

14. Snell, Robin S. and Neil C. Herndon, Jr., "Hong Kong's Code of Ethics Initiative: Some Differences between Theory and Practice," Journal of Business Ethics, Volume 51, Pages 75-89, 2004.

15. Vaught, Bobby C., Raymond E. Taylor, and Steven F. Vaught, "The Attitudes of Managers Regarding the Electronic Monitoring of Employee Behavior: Procedural and Ethical Considerations," American Business Review, Volume XVIII, Number 1, (January), Pages 107-114, 2000.

16. $\mathrm{Wu}$, Chen-Fong, "Research on a Typology of Business Ethics Operation across the Taiwan Strait," Journal of Business Ethics, Volume 52, Pages 229-242, 2004. 